\title{
Polyvalent Scaffolds. Counting the Number of Seats Available for Eosin Guest Molecules in Viologen-Based Host Dendrimers
}

Filippo Marchioni, ${ }^{\dagger}$ Margherita Venturi, ${ }^{\dagger}{ }^{*} *$ Alberto Credi,${ }^{\dagger}$ Vincenzo Balzani $,{ }^{\dagger}, *$ Martin Belohradsky, Arkadij M. Elizarov, Hsian-Rong Tseng, J. Fraser Stoddart, * *

Dipartimento di Chimica "G. Ciamician", Università di Bologna via Selmi 2, I-40126 Bologna, Italy, and

The California NanoSystems Institute and Department of Chemistry and Biochemistry, University of California Los Angeles, 405 Hilgard Avenue, Los Angeles, CA 90095-1569 (USA)

\section{Supporting Information}




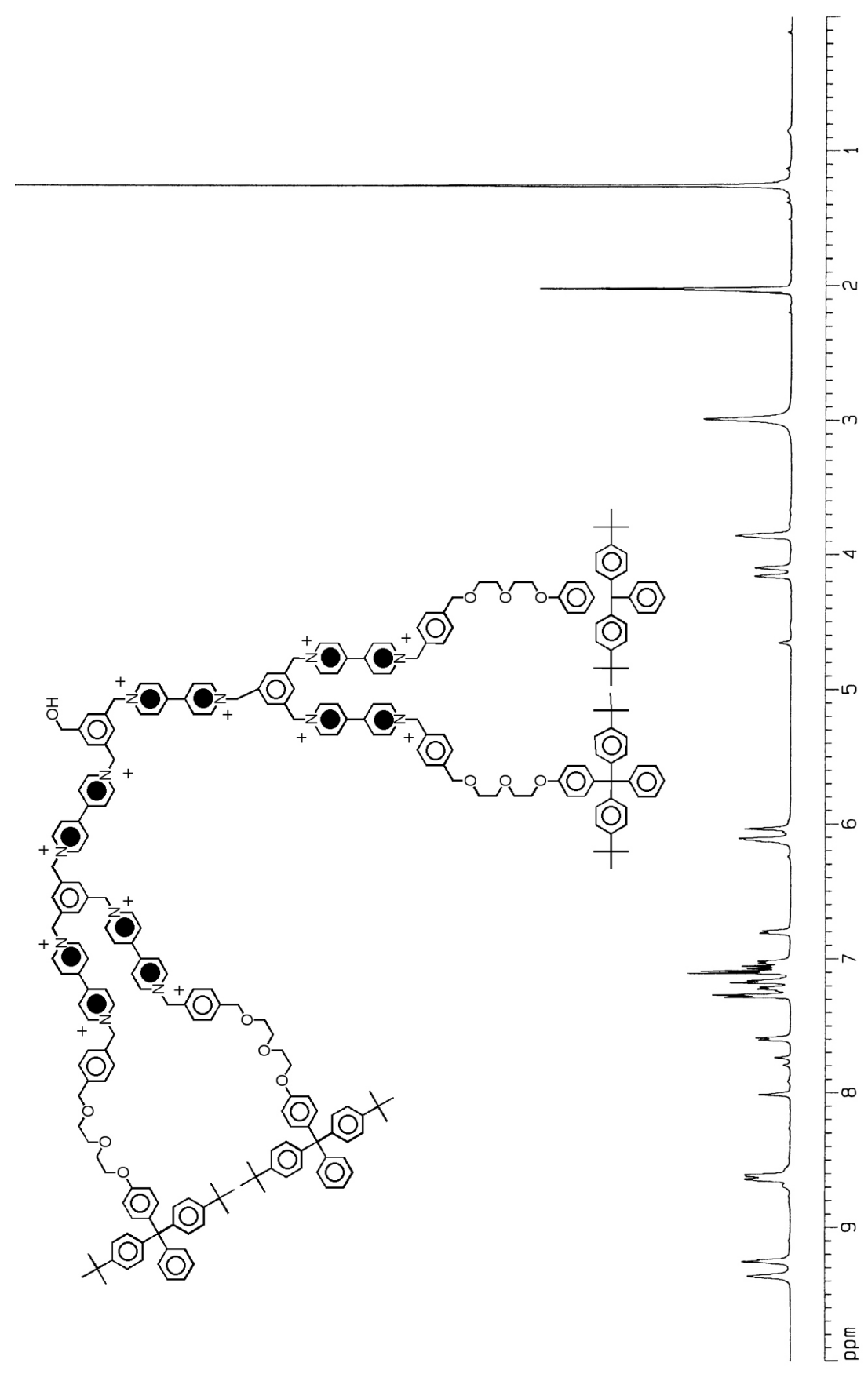

Figure S1. ${ }^{1} \mathrm{H}$ NMR spectrum of $\mathbf{A 6} \cdot 12 \mathrm{PF}_{6}$ at $500 \mathrm{MHz}$ in $\mathrm{CD}_{3} \mathrm{CN}$ at room temperature. 


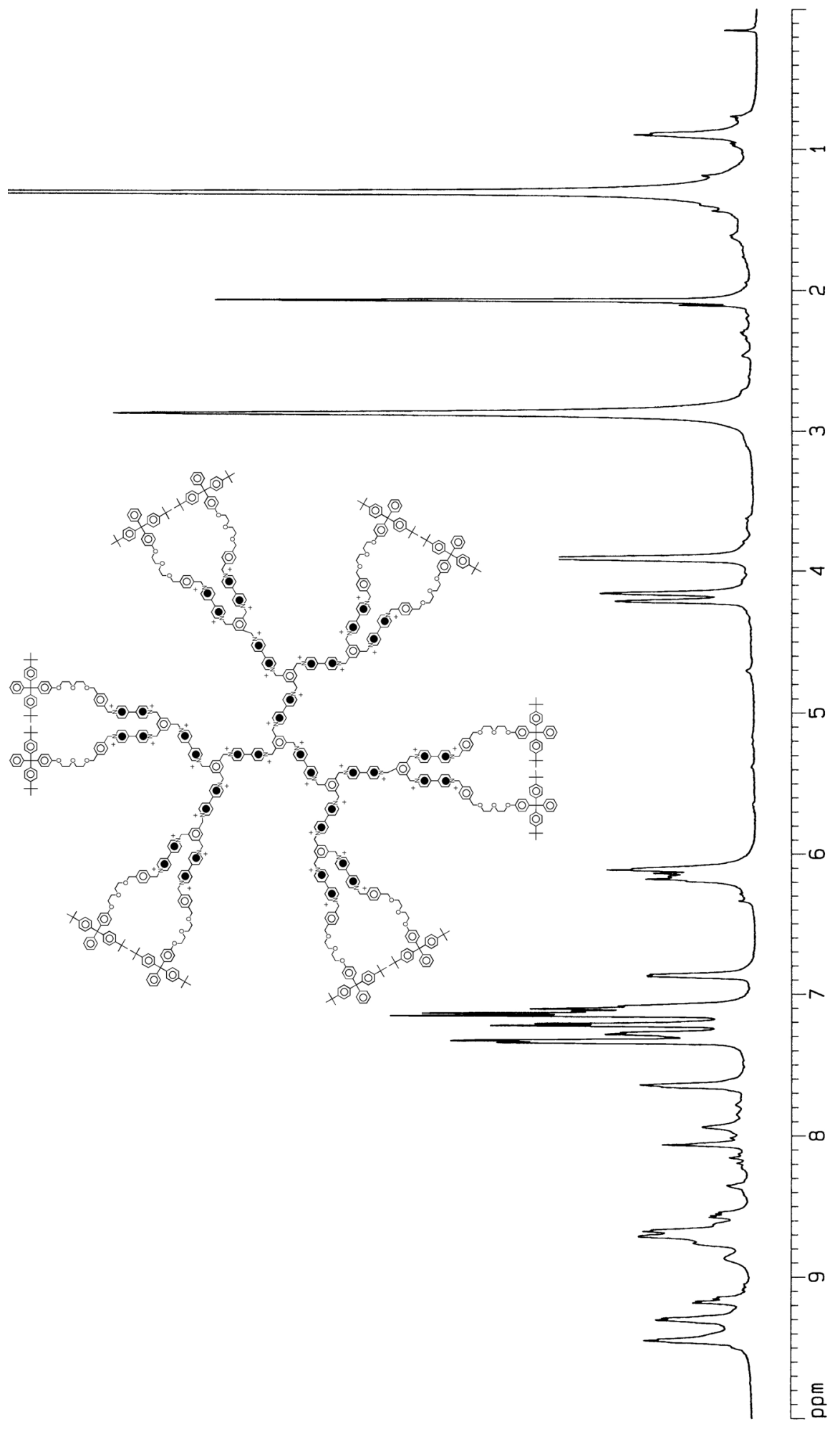

Figure S2. ${ }^{1} \mathrm{H}$ NMR spectrum of $\mathbf{A 2 1} \cdot 42 \mathrm{PF}_{6}$ at $500 \mathrm{MHz}$ in $\mathrm{CD}_{3} \mathrm{CN}$ at room temperature. 